\title{
Circulating von Willebrand factor in inflammatory bowel disease
}

T R J Stevens, J P James, N J Simmonds, D A McCarthy, I F Laurenson, P J Maddison, D S Rampton

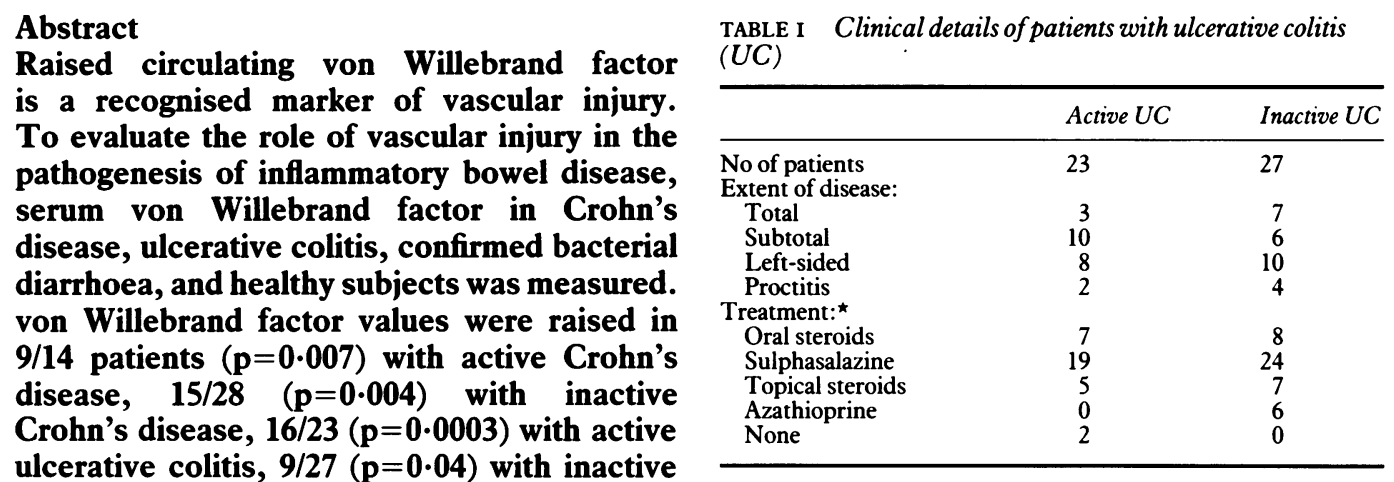
ulcerative colitis, $9 / 27(p=0.04)$ with inactive ulcerative colitis, and $15 / 17 \quad(p=0 \cdot 0001)$ patients with bacterial diarrhoea. Serum von Willebrand factor was unrelated to disease activity in Crohn's disease but was significantly raised in active $(p=0.02)$ compared with inactive ulcerative colitis. In contrast to controls, the detection of von Willebrand factor from inflammatory bowel disease sera and that from fractured endothelial cells was significantly inhibited by the reducing agent, dithiothreitol, suggesting the presence of an additional dithiothreitol sensitive form of the molecule derived from injured endothelial cells in inflammatory bowel disease. That serum von Willebrand factor is raised in quiescent as well as active Crohn's disease is compatible with the proposal that vascular injury is a fundamental abnormality in this disorder. The raised von Willebrand factor values in active inflammatory bowel disease and bacterial diarrhoea could be caused by either vascular injury, occurring secondary to bowel inflammation, or to an acute phase response resulting from endothelial cell stimulation by mediators released during the inflammatory process. Raised circulating von Willebrand factor could contribute to the increased risk of thrombosis associated with active inflammatory bowel disease.

Inflammatory bowel disease is characterised by focal or diffuse inflammation of the alimentary tract. ' Although its aetiology is unknown, intestinal vascular injury has been proposed as a major pathogenic factor. Ultrastructural abnormalities of the intestinal vasculature have been reported in Crohn's disease ${ }^{2}$ and ulcerative colitis, ${ }^{3}$ and affected patients "show various coagulation abnormalities and an increased risk of thrombosis. $^{45}$

Increased circulating von Willebrand factor (factor VIII related antigen) has been proposed as a marker of vascular injury. ${ }^{6}$ von Willebrand factor is a high molecular weight multimeric glycoprotein, synthesised and released by vascu- $\star$ Some patients were on more than one treatment.

lar endothelial cells and megakaryocytes, ${ }^{7}$ that plays an important role in platelet-endothelial cell interactions and stabilising the factor VIII coagulation protein. ${ }^{8}$ Circulating von Willebrand factor is raised in experimental models of vascular injury ${ }^{9}$ and in disorders characterised by overt vascular inflammation. ${ }^{10}$

In this study, by examining serum von Willebrand factor in active and quiescent inflammatory bowel disease, in patients with confirmed bacterial diarrhoea, and in healthy volunteers as controls, we have investigated the role of vascular injury in the pathogenesis of inflammatory bowel disease.

\section{Methods}

PATIENTS WITH INFLAMMATORY BOWEL DISEASE (Tables I and II)

Crohn's disease ( $n=42 ; 14$ with active and 28 inactive disease) and ulcerative colitis $(n=50 ; 23$ with active and 27 with inactive disease) were diagnosed by conventional clinical, radiological, endoscopic, and histological criteria.

Disease activity in Crohn's disease was determined by Harvey's clinical index, " with an additional 1 point for the following laboratory variables: haemoglobin $<12 \mathrm{~g} / 100 \mathrm{ml}$ (men) and $<11 \mathrm{~g} / 100 \mathrm{ml}$ (women); erythrocyte sedimentation rate $>20 \mathrm{~mm} /$ hour; $\mathrm{C}$ reactive protein $>0.8$

TABLE II Clinical details of patients with Crohn's disease (CD)

\begin{tabular}{lrr}
\hline No of patients & 14 & 28 \\
Site of disease: & 6 & 15 \\
Small bowel & 1 & 7 \\
Ileocolonic & 7 & 6 \\
Colonic & 8 & 6 \\
Treatment: & 5 & 13 \\
Oral steroids & 3 \\
Sulphasalazine & 1 & 3 \\
Topical steroids & 3 & 13 \\
Metronidazole & 5 & \\
None & & \\
\hline
\end{tabular}

^Some patients were on more than one treatment.
Infectious Diseases Unit, Rush Green Hospital, Romford, Essex Correspondence Dr T R J Stevens, GI Science Research Unit, 26 Ashfield Street, London E1 2AJ Accepted for publication 2 July 1991 
$\mathrm{mg} / 100 \mathrm{ml}$; platelet count $>500 \times 10^{9} / 1$, and serum albumin $<35 \mathrm{~g} / \mathrm{l}$. Patients with a total score of 6 or more were deemed to have active disease.

Disease activity in patients with ulcerative colitis was assessed by a modified Harvey index: well-being (0-4); number of unformed stools daily, or, if formed, number in excess of three yesterday; rectal bleeding: $(0-3: 0=$ none, $1=$ rarely, $2=$ often, $3=$ with every stool); sigmoidoscopic score $(0-3)^{12}$; extraintestinal complications ( 1 for each item) in addition to the laboratory variables described for Crohn's disease. Ulcerative colitis patients with a total score of 5 or more were deemed to have active disease.

CONTROLS

Seventeen patients with confirmed bacterial diarrhoea (11 before and after recovery), served as disease controls and 21 healthy blood donors as normal controls.

\section{SERIAL MEASUREMENTS OF SERUM VON WILLEBRAND FACTOR}

Serum von Willebrand factor values were measured in paired samples during active and inactive phases of disease in nine patients with Crohn's disease, nine with ulcerative colitis, and 11 with bacterial diarrhoea. Disease activity was defined as shown above.

\section{DETERMINATION OF SERUM VON WILLEBRAND} FACTOR

All serum samples were coded and stored at $-20^{\circ} \mathrm{C}$ until tested. von Willebrand factor was determined by enzyme linked immunosorbent assay (ELISA) using commercially available von Willebrand factor antisera (DAKO corporation). ${ }^{10}$

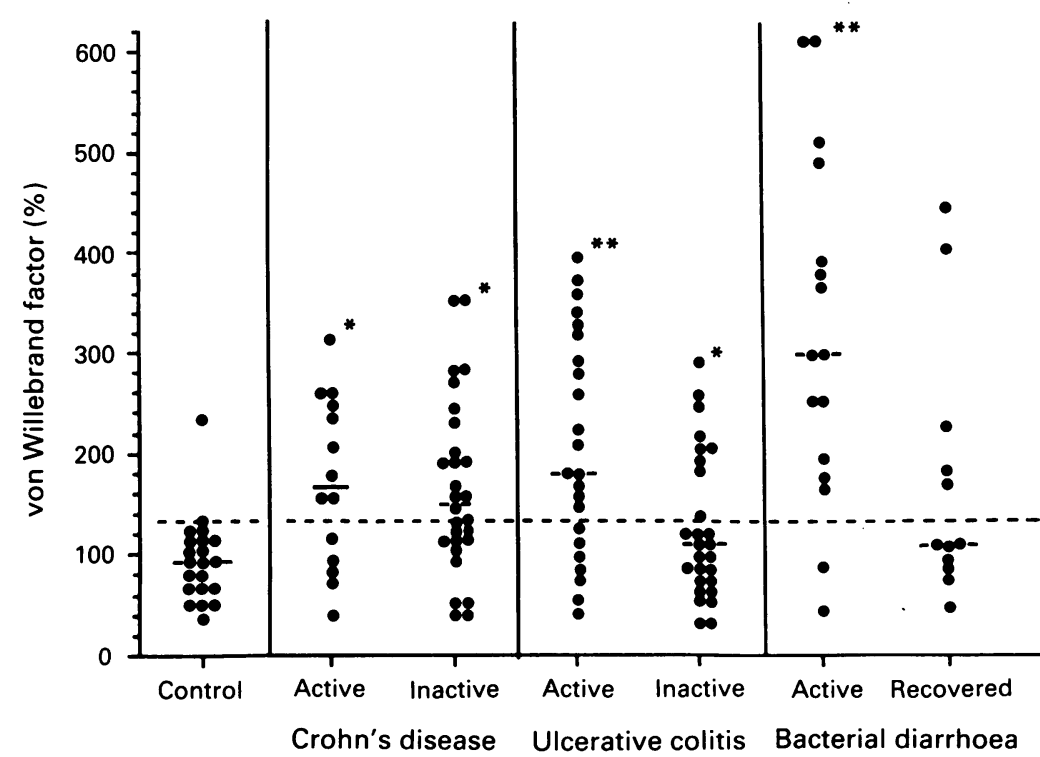

Figure 1: von Willebrand factor concentrations in inflammatory bowel disease and bacterial diarrhoea. von Willebrand factor was assayed in sera by ELISA. Results are expressed as percentage values, calculated from a standard dilution curve constructed from pooled healthy human sera. Horizontal bars represent median values and the upper limit of the normal range is indicated by the broken horizontal line. $\left({ }^{\star}=p<0.05 \mathrm{v}\right.$ control, $\star \star=p<0.05 \mathrm{v}$ inactive disease.)
MicroELISA plates (96 well) were coated with $100 \mathrm{ml}$ of rabbit anti-human von Willebrand factor diluted $1 / 1000$ in $0.05 \mathrm{~mol} / 1$ carbonate buffer ( $\mathrm{pH} \mathrm{9.6)} \mathrm{for} \mathrm{one} \mathrm{hour} \mathrm{at} \mathrm{room} \mathrm{tempera-}$ ture. The plates were then washed in phosphate buffered saline ( $\mathrm{pH} \mathrm{7.4)} \mathrm{containing} 0.05 \%(\mathrm{v} / \mathrm{v})$ Tween 20 (PBS-0.05\% Tween), shaken dry, and $100 \mu \mathrm{l}$ of a diluted standard or sample serum diluted $1 / 40$ in PBS- $0 \cdot 1 \%$ Tween added to duplicate wells, and incubated at room temperature for one hour. PBS- $0 \cdot 1 \%$ Tween $(100 \mu \mathrm{l})$ was also added to six microwells as blanks and a standard curve was determined for each plate by diluting (1/10-1/320) pooled healthy sera (the pooled serum standard had been previously confirmed to correspond to an NIBSC standard plasma for determination of von Willebrand factor. The plates were then washed three times by immersion into PBS- $0.05 \%$ Tween, shaken dry, and $100 \mu$ l of rabbit anti-human von Willebrand factor peroxidase conjugate diluted $1 / 1000$ in PBS- $0.1 \%$ Tween were added to each well and incubated a further hour at room temperature. Finally, plates were washed three times by immersion in PBS- $0.05 \%$ Tween and then once in citrate phosphate buffer ( $\mathrm{pH} \mathrm{5.0)}$ before addition of $100 \mu \mathrm{l}$ of $0.56 \mathrm{mg} / \mathrm{ml} 1.2$ orthophenylenediamine dihydrochloride, dissolved in citrate phosphate buffer ( $\mathrm{pH} 5 \cdot 2$ ), supplemented with hydrogen peroxide as substrate. Microwell plates were continuously agitated during colour development and absorbance values were measured at $492 \mathrm{~nm}$ on an automated ELISA reader (Dynatech MR 580). The average readings from the blanks were subtracted from all others and these were then read off the standard curve and multiplied by the dilution factor to give values of von Willebrand factor as a percentage of that in the pooled standard serum.

\section{DITHIOTHREITOL-MODIFIED ELISA}

Serum samples or supernatants from cultured human umbilical vein endothelial cells (HUVE), subjected to four freeze-thaw cycles and then centrifuged at $3000 \mathrm{~g}$, were incubated for 10 minutes with dithiothreitol (DTT) $(0 \cdot 6-2 \cdot 4$ $\mathrm{mmol} / 1$ in PBS- $0.1 \%$ Tween) at $37^{\circ} \mathrm{C}$ as described by Rose $e \mathrm{al}^{13}$ before determination of von Willebrand factor by ELISA.

\section{STATISTICAL ANALYSIS}

Results within the normal range were defined as those values below the 95th centile value of the control group. Statistical significance of differences in group median values were determined by two tailed Mann-Whitney U test. Correlations were sought using Spearman's rank correlation test. Statistical differences in the serial von Willebrand factor studies were determined by Wilcoxon's (two tailed) signed rank test.

\section{Results}

SERUM VON WILLEBRAND FACTOR

Median serum von Willebrand factor concentrations were raised in all inflammatory bowel 
TABLE III Relation between extent of disease and serum von Willebrand factor ( $v W f$ in ulcerative colitis (UC)

\begin{tabular}{|c|c|c|c|c|c|c|}
\hline \multirow{2}{*}{$\begin{array}{c}T \\
\text { Extent of disease }\end{array}$} & \multicolumn{3}{|c|}{ Active UC } & \multicolumn{3}{|c|}{ Inactive UC } \\
\hline & $\overline{N o}$ & $v W f(\%)$ & $(S D)$ & $\overline{N o}$ & $v W f(\%)$ & $(S D)$ \\
\hline $\begin{array}{l}\text { Total } \\
\text { Subtotal } \\
\text { Left -sided } \\
\text { Proctitis }\end{array}$ & $\begin{array}{r}3 \\
10 \\
8 \\
2\end{array}$ & $\begin{array}{l}242 \\
198 \\
215 \\
205\end{array}$ & $\begin{array}{l}(79) \\
(108) \\
(107) \\
(162)\end{array}$ & $\begin{array}{r}7 \\
6 \\
10 \\
4\end{array}$ & $\begin{array}{l}129 \\
115 \\
132 \\
197\end{array}$ & $\begin{array}{r}(53) \\
(34) \\
(64) \\
(124)\end{array}$ \\
\hline
\end{tabular}

TABLE IV Relation between site of disease and serum von Willebrand factor ( $v W f$ in Crohn's disease $(C D)$

\begin{tabular}{lllllllll}
\hline & \multicolumn{3}{l}{ Active $C D$} & & & \multicolumn{2}{l}{ Inactive $C D$} \\
\cline { 2 - 3 } Site of disease & No & $v W f(\%)$ & $(S D)$ & & $N o$ & $v W f(\%)$ & $(S D)$ \\
\hline Small bowel & 6 & 174 & $(63)$ & & 15 & 173 & $(82)$ \\
Ileocolonic & 1 & 144 & & & 7 & 120 & $(61)$ \\
Colonic & 7 & 168 & $(112)$ & & 6 & 175 & $(110)$ \\
\hline
\end{tabular}

disease groups compared with normal healthy controls (Fig 1). Sixty four per cent $(p=0 \cdot 007$ for group median $v$ control) of patients with active Crohn's disease and $54 \%(\mathrm{p}=0.004)$ with inactive disease had von Willebrand factor concentrations above normal $(>$ healthy control 95 th centile value, that is $132 \%)$. In the ulcerative colitis group, $70 \%(p=0.0003)$ of patients with active disease and $33 \%(\mathrm{p}=0.04)$ with inactive disease had abnormally raised von Willebrand factor concentrations. Patients with inactive ulcerative colitis expressed significantly lower serum von Willebrand factor values than those with active disease $(p=0 \cdot 02)$. When von Willebrand factor concentrations in the Crohn's disease and ulcerative colitis groups were examined as a function of individual clinical and laboratory parameters of disease activity, no significant correlations were found. In particular, there was no relation between serum von Willebrand factor concentrations and $\mathrm{C}$ reactive protein concentrations in the clinically inactive Crohn's disease subgroup. von Willebrand factor

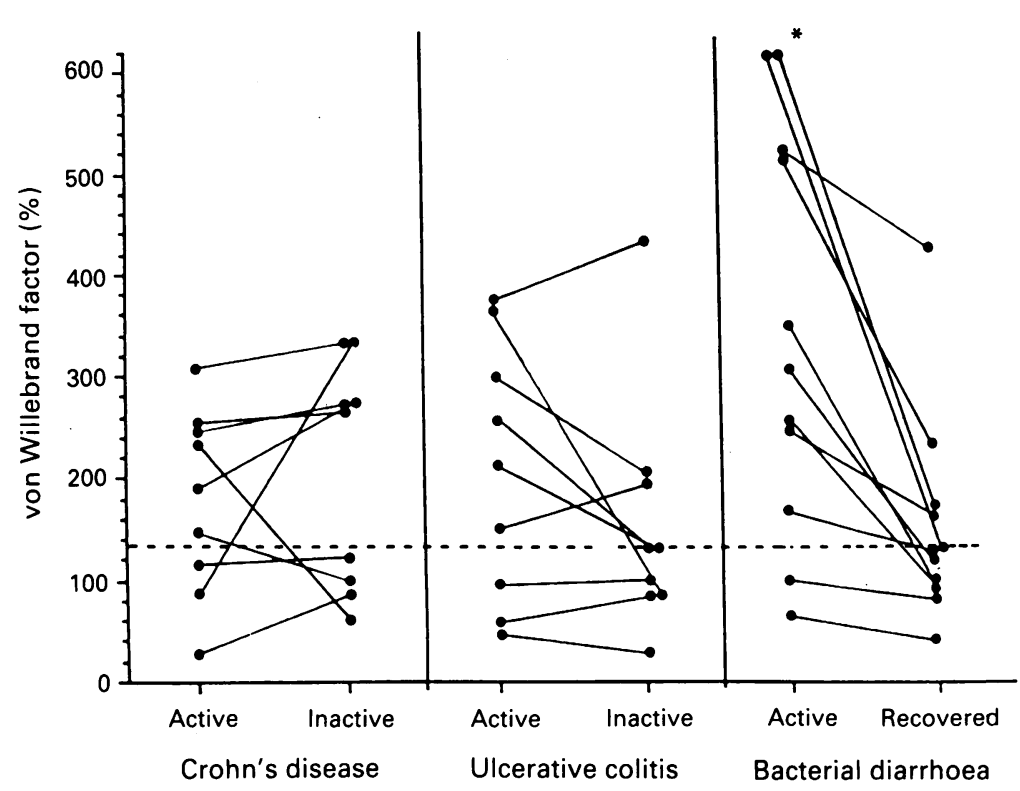

Figure 2: Serial von Willebrand factor factor concentrations in inflammatory bowel disease and bacterial diarrhoea. Paired serum samples were obtained during active and inactive stages of disease and assayed for von Willebrand factor by ELISA. Results are expressed as percentage values and are calculated from a standard dilution curve constructed from pooled healthy human sera. The broken horizontal line represents the upper limit of the normal range. $(\star=p<0.005 \mathrm{v}$ inactive disease. $)$ values were also unrelated to the site of disease in Crohn's disease (Table IV), extent of disease in ulcerative colitis (Table III), or drug treatments administered in either group.

High concentrations of serum von Willebrand factor were also observed in $88 \%$ of patients with confirmed bacterial diarrhoea $(p=0.0001)$.

Serial studies in inflammatory bowel disease patients showed no statistically significant differences in circulating von Willebrand factor when a change in disease activity occurred (Fig 2). However, a fall in circulating von Willebrand factor accompanied the transition from active to inactive disease in 5 of $9(\mathrm{p}=\mathrm{NS})$ patients with ulcerative colitis. von Willebrand factor values also fell $(p=0.0003)$ in all patients recovering from bacterial diarrhoea. No such trends were observed in patients with Crohn's disease, where a change from active to inactive disease was accompanied by a rise in serum von Willebrand factor in $7 / 9$ patients.

SENSITIVITY OF VON WILLEBRAND FACTOR FROM INFLAMMATORY BOWEL DISEASE SERA TO DTT

Preincubation of sera with the reducing agent DTT $(0.6-2.4 \mathrm{mmol} / \mathrm{l})$ reduced, in a dose dependent manner, the amount of von Willebrand factor subsequently detected by ELISA (data not shown). Maximum inhibition by DTT, however, was related to the initial von Willebrand factor concentration: subjects with a raised concentration - that is, inflammatory bowel disease and bacterial diarrhoea patients - were more susceptible to inhibition than controls. A plot of the initial concentration against maximal inhibition by DTT (Fig 3) shows that a proportion of the von Willebrand factor measured by ELISA was completely resistant to the effects of DTT and that this proportion was greatest in subjects with normal serum von Willebrand factor concentrations. When von Willebrand factor released from fractured cells was tested for DTT sensitivity, the results were similar to those obtained from sera containing high concentrations (Fig 3).

\section{Discussion}

Median serum von Willebrand factor concentrations were significantly raised in patients with Crohn's disease, ulcerative colitis, and bacterial diarrhoea compared with healthy controls. Serum concentrations were significantly higher in patients with active ulcerative colitis than those with inactive disease (Fig 1). Furthermore, the transition from active to inactive disease in nine patients with ulcerative colitis was accompanied by a fall in von Willebrand factor in five of them (Fig 2). The high values of circulating von Willebrand factor in patients with active bacterial diarrhoea also fell towards normal on recovery. In contrast, no relation between serum von Willebrand factor concentrations and disease activity was found in Crohn's disease patients (Figs 1 and 2).

Our results confirm and extend those of Gris et $a l^{1+}$ who reported raised plasma von Willebrand factor concentrations in a small mixed group of patients with active inflammatory bowel 


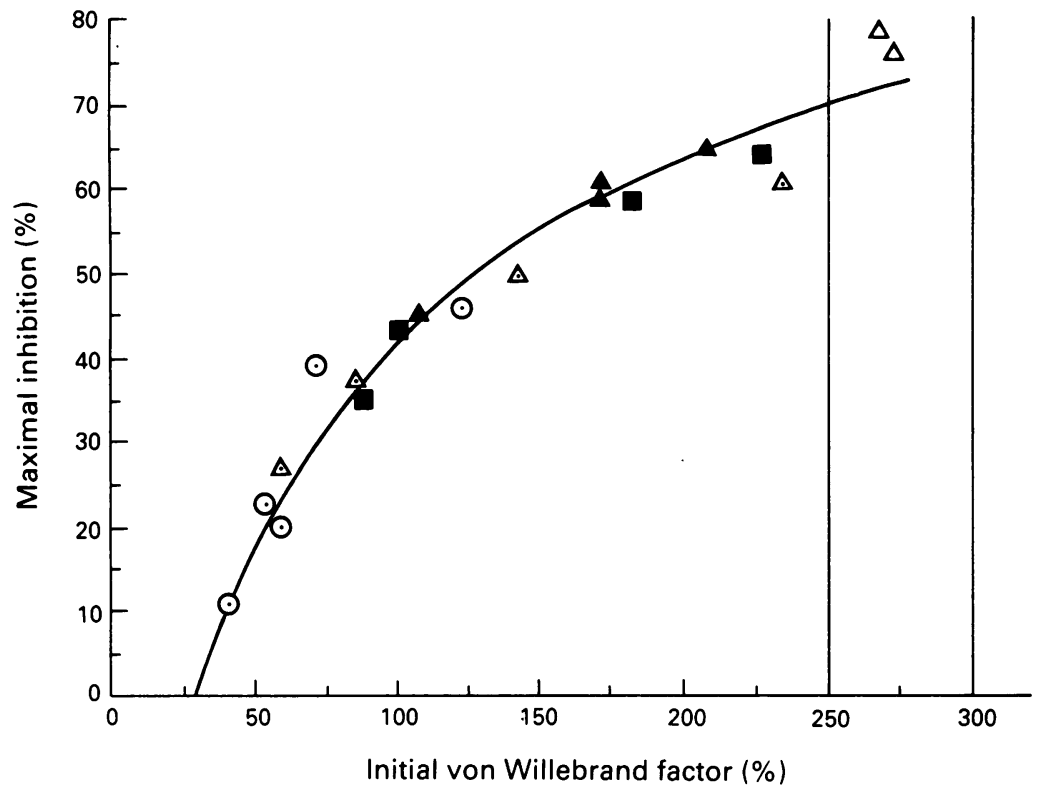

Figure 3: Relation between the initial von Willebrand factor concentration and maximum inhibition by dithiothreitol in serum samples from healthy subjects $(\odot)$, Crohn's disease $(\Delta)$, ulcerative colitis ( $)$, bacterial diarrhoea $(\mathbf{\Delta})$ and freeze thawed endothelial cell supernatant $(\triangle)$. von Willebrand factor values were determined by ELISA after sample incubation for 10 minutes at $37^{\circ} \mathrm{C}$ with buffer or a maximal inhibitory concentration of dithiothreitol (DTT). Results were determined as previously described and maximal inhibition is given as $([v W F]+b u f f e r-[v W F]+D T T) /([v W F]+b u f f e r)$.

disease (four ulcerative colitis, three Crohn's disease) compared with another group with quiescent disease (six ulcerative colitis, four Crohn's disease) and controls. The reasons for the discrepancy between our findings and those of Zielen et $a l,{ }^{15}$ who reported that von Willebrand factor concentrations in Crohn's disease fell in remission, are obscure: they could relate to the previous authors' study of children, or use of rocket immunoelectrophoresis for the measurement of von Willebrand factor.

Raised circulating von Willebrand factor concentrations are found in several acute inflammatory disorders. ${ }^{16}$ The extent to which the high serum concentrations in active inflammatory bowel disease and bacterial diarrhoea reflect vascular injury or the manifestation of an acute phase response to other inflammatory mediators ${ }^{16}$ is unknown: candidate inflammatory mediators include bacterial lipopolysaccharide, interleukin-1, tumour necrosis factor, and histamine. However, the raised serum von Willebrand factor concentrations in patients with normal $C$ reactive protein values and other laboratory markers of inflammation in patients with clinically inactive Crohn's disease, argues against an acute phase response in these subjects. Indeed, this observation suggests the presence of a persistent stimulus causing release of von Willebrand factor from the vascular endothelium and is compatible with the proposal that vascular injury is an early event in the pathogenesis of the disease. $^{2}$

The inverse relation between endothelial von Willebrand factor and complement deposition in inflammatory bowel disease reported by Halstensen et $a l^{17}$ may give some clues to the possible mechanism of von Willebrand factor release. Hattori et $a l^{18}$ have recently reported that von Willebrand factor release from cultured endothelium in vitro is stimulated by the C 5 b- 9 membrane attack complex (MAC). It is possible that activated complement components are partly responsible for the raised serum von Willebrand factor in inflammatory bowel disease since: (a) in ulcerative colitis, deposition of the complement MAC, ${ }^{19}$ reduced staining of endothelial von Willebrand factor, ${ }^{17}$ and the raised circulating von Willebrand factor concentrations reported here are each related to disease activity; (b) in Crohn's disease, increased secretion of C4 and $\mathrm{C} 3$ from perfused unaffected jejunum was, like serum von Willebrand factor, found in quiescent as well as active disease. ${ }^{20}$

The increased sensitivity of von Willebrand factor to DTT inhibition in subjects with raised serum concentrations, and the occurrence of a greater proportion resistant to DTT in controls, may indicate the presence of more than one form of von Willebrand factor in the circulation. The data suggest that at least a proportion of the von Willebrand factor in inflammatory bowel disease is derived from injured endothelial cells and that this proportion is highly sensitive to DTT. In our studies, von Willebrand factor released from fractured HUVE was more sensitive to inhibition by DTT than that released constitutively - that is, the von Willebrand factor circulating in normal healthy subjects - and probably represents the large multimeric forms stored in the Weibel-Palade bodies, which are released by specific or injurious stimuli in vitro. ${ }^{7}$ Further investigation into the molecular composition of von Willebrand factor by agarose gel electrophoresis is under way to clarify the presence of abnormal (large multimer) forms in the circulation of inflammatory bowel disease patients.

While the increased incidence of venous thrombosis in inflammatory bowel disease could be partly related to endothelial cell damage, it has also been attributed to a hypercoagulation state. ${ }^{5}$ The importance of raised circulating von Willebrand factor in such a scenario is unknown. However, if the circulating von Willebrand factor in inflammatory bowel disease consists, as is suggested by our results, partly of the storage form of the molecule, which contains large protein multimers that are potent mediators of platelet adhesion/aggregation reactions, it may play a role in the pathogenesis of thrombosis as well as being a marker of vascular injury in inflammatory bowel disease. More work is needed to evaluate this hypothesis.

Published as an abstract in Gut 1990; 31: Al169. We thank the National Association for Colitis and Crohn's Disease for financial support.

1 Shearman DJC, Finlayson NDC, eds. Diseases of the gastrointestinal tract and liver. London: Churchill Livingstone, 1982: 332-46.

2 Wakefield AJ, Sawyerr AM, Dhillon AP, Pittilo RM, Rowles PM, Lewis AAM, et al. Pathogenesis of Crohn's disease: multifocal gastrointestinal infarction. Lancet 1989; ii: 105762 .

3 Fairburn RA. Aetiology of ulcerative colitis: a vascular hyothesis. Lancet 1973; ii: 697-9.

4 Koenigs KP, McPhedran P, Spiro HM. Thrombosis in inflammatory bowel disease. $\mathcal{F}$ Clin Gastoenterol 1987; 9: 627-31

5 Talbot RW, Heppel J, Dozois RR, Beart RW. Vascular complications of inflammatory bowel disease. Mayo Clin Proc 1986; 61: 140-5.

6 Kahaleh MB, Osborn I, Le Roy EC. Increased factor VIII/von Willebrand factor and von Willebrand activity in scleroderma and Raynaud's phenomenon. Ann Intern Med 1981; 94: 482-4.

7 Handin RI, Wagner DD. Molecular and cellular biology of von Willebrand factor. Prog Hemost Thromb 1988; 9: 233-57. 
8 Morisato DK, Gralnick HR. Selective binding of human FVIII/von Willebrand protein to human platelets. Blood 1980; 55: $9-15$.

9 Novotney MJ, Turrentine MA, Johnson GS, Adams HR. Experimental endotoxaemia increases plasma von Willbrand factor antigen concentrations in dogs with and without free radical scavenger therapy. Circ Shock 1987; 23 . 205-13.

10 James JP, Stevens TRJ, Hall ND, Maddison PJ, Goulding NJ Silman A, et al. Factor VIII-related antigen in connective issue disease patients and relatives. Br f R heumatol 1990 29: 6-9.

11 Harvey RF, Bradshaw JM. A simple index of Crohn's disease activity Lancet 1980 ; i: 514-5.

12 Baron JH, Connell AM, Lennard-Jones JE. Variation between observers in describing mucosal appearances in proctitis. BMF 1964; i: 89-92.

13 Rose PE, Struthers GS, Robertson M, Kavi J, Chant I, Taylor CM. Factor VIII von Willebrand protein in haema CM. Factor VIII von Willebrand protein in haemolytic uraemic syndrome and systemic vasculitides. Lancet 1990

14 Gris JC, Schved JF, Raffanel C, Dubois A, Agiular-Martine\% $P$, Arnaud A, et al. Impaired fibrinolytic capacity in patients with inflammatory bowel disease. Thromb Haemost 1990; 63: $472-5$
15 Zielen S, Bender SW, Kreuz W, Posselt HG, Solem E, Scharrer I. Crohn's disease activity: assessment by factor VIII coagulation proteins. I Ped Gastroenterol Nutr 185; 4: $730-4$

16 Pottinger BE, Read RC, Paleolog EM, Higgins PG, Pearson JD. von Willebrand factor is an acute phase reactant in man Thromb Res 1989; 5: 387-94

17 Halstensen TS, Mollnes TE, Brandtzeag P. Persistent complement activation in submucosal blood vessels of active inflammatory bowel disease: immunohistochemical evidence. Gastroenterology 1989; 97: 10-9.

18 Hattori R, Hamilton K, McEver RP, Sims PJ. Complement proteins $\mathrm{C} 5 \mathrm{~b}-9$ induce secretion of high molecular weight proteins C5b-9 induce secretion of high molecular weight multimers of endothelial von Willebrand factor and translocation of granule membrane protein GMP-
surface. F Biol Chem 1989; 264: 9053-60.

19 Halstensen TS, Mollnes TE, Fausa O, Brandtzaeg P. Deposit of terminal complement complex (TCC) in muscularis mucosae and submucosal vessels in ulcerative colitis and Crohn's disease of the colon. Gut 1989; 30: 361-6.

20 Ahrenstedt O, Knutson L, Nilsson B, Nilsson-Ekdahl K, Odlind $\mathrm{B}$, Hallgreen R. Enhanced local production of complement components in the small intestines of patient with Crohn's disease. N Eng $\mathcal{F}$ Med 1990; 322: 1345-9. 